\title{
An Innovative Viable Model for Community-Owned Solar PV Projects without FIT: Comprehensive Techno-Economic Assessment
}

\author{
Pegah Mirzania a Nazmiye Balta-Ozkana Andy Ford ${ }^{\text {b }}$ \\ a Cranfield University, Bedfordshire, b London South Bank University, London, SE1 0AA, Corresponding author: p.mirzania@cranfield.ac.uk
}

\begin{abstract}
:
The progressive withdrawal of the Feed-in-Tariff provided by the UK government has left community-owned solar photovoltaic projects facing significant financial challenges. They urgently need to develop alternative business models that will enable them to develop new projects and recuperate their costs in this post-subsidy era. One promising possibility is the incorporation of storage technology. However, currently it cannot be denied that the financial viability of this type of model is in question. This paper investigates whether and how integrated solar and battery storage system would be financially viable, using the System Advisor Model as a simulation tool to conduct techno-economic analyses.

This paper proposes an innovative model designated as, the 'Community-owned Energy Storage' model. This model proposes that community-owned solar projects should sell their locally generated electricity under a Time of Use Power Purchase Agreement (TOU PPA). Results demonstrated under the developed model of communityowned solar projects can fully restore the economic viability and become financially attractive if they could utilise a combination of TOU PPA and demand-side response (DSR) services. This paper, therefore, recommends that the UK government should promote and facilitate the TOU PPA and encourage suppliers to involve local energy projects within the provision of DSR.
\end{abstract}

Key Words: Techno-economic analysis, community-owned solar PV, Battery storage, Business model, Demand side response

\section{Introduction}

Despite consistent growth in the world's renewable energy market, current carbon emission targets are likely to be missed as public opposition to the development of renewable energy resources continues to pose a challenge (Everett, Robert et al., 2012; International Energy Agency, 2016 and 2017; United Nations Foundation, 2015). One development that could make a significant contribution towards the achievement of a low carbon future is the decentralisation of energy generation and the greater involvement of local communities. Many such community renewable energy (CRE) projects have been initiated around the UK in recent years, most of them using small-scale solar photovoltaic (PV) generation to supply electricity (Mirzania et al, 
2019) .

In recent years, the UK government has recognised the potential of CRE projects and has formulated policies to encourage them. One of the most important of these was the Feed-inTariff (FiT) scheme, which provided payments for the generation and export of the surplus electricity they generated. Since its introduction in 2010, this subsidy has been essential to the financial viability of many CRE projects (Cherrington et al, 2013; Nolden, 2013). The decision in 2016 to dramatically reduce it and to progressively withdraw it altogether from March 2019 has seriously undermined these initiatives (Ofgem, 2019). Solar PV projects, in particular, are finding it difficult to expand (Mirzania et al., 2019) . If the UK's CRE groups are to prosper or even survive in this post-subsidy situation, an alternative business model is urgently needed to ensure viability of CRE projects.

Asmus (2008) defined community-owned solar PV business models as the collective participation of people who do not have access to renewable energy resources, fiscal capacity or ownership rights in renewable energy activities, purchasing shares in the total output from energy generation of solar technologies, or supplying electricity to community buildings (community centres, schools) without any need to pay an upfront cost or tackle installation challenges.' This type of business model can lead to more cost efficiency and therefore more efficient energy projects (Huijben \& Verbong, 2013). Typically, the CRE organisation leases a roof from a community building, like a local school, but retains ownership of the solar technology it constructs there and any associated revenue streams (FiT). The community building can buy the generated solar electricity from CRE projects at a much lower price than that available from the grid and thus save a significant amount of money (Figure 1) (Mirzania et al., 2019).

Figure 1: Typical Community-owned Solar Business Model 
Existing community-owned solar projects are not financially viable and has following drawbacks for two reasons:

(a) Their business models are heavily dependent on the FiT subsidy scheme, which is now being withdrawn.

(b) They are still significantly dependent on grid:

I. Because the intermittent nature of solar PV means that occupants sometimes have to purchase electricity from the grid at high price

II. Because surplus locally-generated electricity has to be exported to the grid rather than being consumed by local residents, means that there are still electricity losses through electricity transportation.

To maximise the economic benefit of this model, all the electricity generated by the solar PV system should be consumed locally. However, during weekends and summer holidays (a peak time for solar generation), schools are closed, so the demand for electricity is low. As a result, the surplus energy generated has to be exported to the grid. Conversely, when the demand for electricity may exceed what the solar PV installation can provide, so extra electricity must be drawn from the grid. Although some payment may be made for the exported surplus energy in the summer, it will be considerably less than the cost of buying this energy back from the grid when it is needed.

One possible solution to overcome these weaknesses and ensuring the sustainable generation of Solar PV is the integration of battery storage with solar PV generation. Therefore, this paper uses a high school located in London, England as a base to investigate how community-owned solar-plus-storage can be structured to be viable and self-sustaining model for community solar PV projects. 
Energy storage is not a new concept, as pumped hydro, flywheels, and stored heat have been part of the UK energy system for many years. However, recent advances in the design of rechargeable batteries and global growth in their manufacture have provided more innovative opportunities for smarter storage solutions and business models. The cost of batteries is falling and their performance is improving; together with advances in digital monitoring and communication technology, this means that small-scale solar PV technology can now be combined with smart storage of any excess energy produced, a development that could potentially revolutionise the energy market (KPMG LLP, 2015 and 2016 ; Regen SW, 2016).

Widespread adoption of this solar-plus-storage technology would lead to a marked reduction in demand for electricity from the grid, a phenomenon called 'load defection'(Bronski et al., 2015). Conventional energy companies in the US and Australia are already becoming concerned about the effect of this on their future profitability (10:10 Climate Action, 2016; Maloney, 2018). As a result, some scholars call for a more innovative pricing mechanism that takes into account a higher fixed cost, peak pricing, capacity charges and services required by domestic households which might mean higher bills for some consumers (Faerber et al., 2018).

Load defection might well mean that the cost of grid electricity rises, which would penalise households that still depend on the grid because they cannot afford to install their own domestic solar-plus-storage technology. This is one reason for the importance of community-owned projects; they could address this threat to low-income households by enabling all the consumers in a locality to benefits from installation of solar-plus-storage projects not just the ones wealthy enough to invest in their own storage technology.

Research is needed, however, to explore the full implications of such a revised business model 
for CRE projects. This paper use high school located in London, England characterised by a typical electrical load profile as specified by the UK Energy Research (UKERC, 2013).

The purpose of this study is threefold:

1. To investigate techno-economic feasibility of integrating community-owned solar PV and storage.

2. To investigate how community-owned solar-plus-storage can be structured to provide demand-side response and electricity balancing services.

3. To develop innovative and financially viable business model for the operation of community-owned solar PV projects in the post-subsidy era.

Various scholars have begun to explore the potential opportunities of integrating battery storage and RE, such as Jones et al (2017), who investigate the financial viability of solar PV systems, including battery storage within non-domestic buildings in the absence of FiT. Bruch \& Müller (2014) and Hoppmann et al (2014) have conducted a similar study for residential buildings in Germany. Mariaud, et al (2017) and Sani Hassan, et al., (2017) investigated the feasibility of integrating PV and storage for non-domestic buildings in the UK with various rate of FiT and electricity prices. The economic feasibility of using storage systems to implement peak shaving (reducing electricity demand during peak price period) has also been explored by Telaretti et al. (2016). Overall, these studies conclude that, in today's market conditions, the effect on the profitability of investing in storage is low. This could be due to the fact that all studies have only considered one application and service of electricity storage, whereas He et al. (2011), Stephan et al., (2016) and Gardiner et al., (2020) highlighted the importance of combining different types of battery storage applications in order to increase the financial viability of solar PV and storage projects. But neither of these papers looked at the financial impact of combining different types of battery storages on viability of solar PV when the subsidies are not available. Consequently, this paper investigates the financial viability of 
the integration of solar PV and electricity storage considering different applications of battery storage (including providing balancing and demand-side services) for community-owned solar PV projects in the post-subsidy conditions. This paper presents a novel model for the operation of community-owned solar PV in the UK which makes these projects self-sustaining. This model enables community and citizen investors to be involved in the generation of RE and grid balancing services even when grants and subsidies are not available.

Section 2 survey literature on emerging business models. Section 3 gives an overview of the research tool and analytical framework which is employed for developing a novel business model for community-owned solar projects. Section 3 then reports the results and Section 4 makes recommendations and proposes alternative policy approaches.

\section{Literature Review}

After FiT reduction the UK's Community Renewable Energy (CRE) sector and in particular community-owned solar PV projects faced financial challenges and must consider alternative business models to ensure the economic viability of its projects, therefore, research into business model innovations have gained increasing attention (Mirzania, 2018). 10:10 Climate Action, (2016) and Mirzania et al., (2019) conducted qualitative research among community energy organisations to investigate alternative business models that CRE projects can under post-subsidy condition (10:10 Climate Action, 2016). Hall \& Roelich (2016) evaluated the current business model of existing local supply models, based on the value prepositions and value capture. RegenSW and Scown (2016) published a report on different local supply models available around the UK in 2016. Furthermore, a few pilot projects across the UK has been undertaken by CRE projects in order to investigate an alternative business model (Western Power Distribution \& Regen SW, 2017 and Energy local, 2018). The sunshine Tariff was a pilot project undertaken by Waderbridge Renewable Energy Network (WREN). The project 
was run between May and September of 2016 in North Cornwall to test the concept of linking DSR to local solar energy and providing grid constraint management. The primary aim of this project was to connect solar farm in Cornwall, which is a constrained area, without creating any net effect results issues at higher voltage from the connection of distributed and intermittent generations (Western Power Distribution, 2015). The Sunshine Tariff project demonstrated that DSR based on time of use in domestic buildings is not yet practical due to the lack of half hourly measurement in many domestic buildings and the challenges and difficulties associated in changing suppliers (Western Power Distribution \& Regen SW, 2017). The sunshine tariff project had two main weaknesses which deemed it unsuccessful. The model was only tested in domestic buildings without any form of flexibility sources such as batteries or electric cars and therefore, in order for the user to shift their electricity demands to the middle of the day, they required to be home during this period which was unrealistic. This project overlooked the importance of electricity storage in the model. Providing DSR alongside battery storage may provide greater flexibility for intermittent energy sources like solar which has previously been overlooked in literature. Further research into incorporating energy storage with solar PV at local level is needed.

However, with the reduction of the FiT rates, integrating battery storage and renewable energy is an idea that has gained increasing attention and is now considered as a potential option for ensuring the sustainable generation of solar PV (Jones et al., 2017, Department of Business Energy and Industrial Strategy and Ofgem, 2017). Based on the current UK regulation and available revenue streams the business model of renewable energy alongside storage would be the most promising business model for the majority of CRE projects which faced financial challenges after FiT reduction (Mirzania et al., 2019). Nevertheless, currently it cannot be denied that the financial viability of this type of model is still in question, and further research is needed to assess its feasibility (Eunimia, 2016). Consequently, this paper aims to investigate 
how solar PV and storage can be combined to provide a combination of DSR, peak shaving and balancing services and in return create financially viable community-owned solar PV projects in the absence of FiT.

\subsection{Theory: The Business Model Concept}

Although the concept of the business model has been increasingly used as an analytical tool among both practitioners and academics, since the mid-1990s (Huijben \& Verbong, 2013), there is no uniform definition of the business model within the existing literature. Richter (2011), refers to the business model as a structural framework that defines a firm's organisational and financial foundation. Bidmon \& Knab, (2014) argue that the business model can play a significant role in the stabilisation of technological innovation. Osterwalder (2004) describes the business model as the means for an organisation to create and deliver value.

Four fundamental aspects of any business model framework are frequently identified by researchers using this tool: value proposition; customer interface; infrastructure; and revenue model (Figure 2) (Bocken et al. 2014, Aslani and Mohaghar, 2013; Osterwalder, 2004; Richter, 2011).

- Value proposition identifies the economic return from a product or service offered by a firm (Bocken et al. 2014).

- Customer interface describes the communication between a company and its target market, and the types of relationships that can be established with this particular customer segment.

- Infrastructure encompasses the ways a firm can capture value and earn revenue through the services and goods it provides (Bocken et al., 2014). 
- Revenue model explores the potential income that can be generated from a business as well as the costs involved its operation.

\section{Figure 2: Conceptualisation of the Business Model}

Source: (Osterwalder, 2004)

Business Model Canvas is the most comprehensive business characterisation framework available and has been employed by many scholars in the field of renewable energy projects, including Aslani and Mohaghar (2013) Johnson and Suskewicz (2009), Osterwalder (2004) and Richter (2011). Huijben \& Verbong (2013) have particularly highlighted how the analysis obtained using this business model mapping tool can facilitate the design of innovative and experimental business models.

\section{Method}

\subsection{Simulation using System Advisor Model (SAM) Software}

Several types of simulation software were considered as possible tools for analysing the feasibility of a solar-plus-storage business model in the UK's post-subsidy situation, including SAM, HOMER and RETscreen.

RETScreen is a renewable energy technology management tool that provides excel spreadsheets designed to calculate a large number of valuable financial indicators. It's main shortcoming as far as this study is concerned is that the input for solar radiation is not loaded daily, so fluctuations in renewable energy generation are not taken into account (Lai \& Mcculloch, 2017). By contrast, SAM supports sub-hourly simulations and can handle weather data updated at one minute intervals (Gilman, 2014).

HOMER is an optimisation software package designed to simulate different types of renewable energy based on Net Present Value (NPV). It offers a sensitivity analysis for models with different solar PV and storage capacity to determine the optimal size of the system. Its main 
drawback is that it requires a great deal of computation time due to the large number of cases it assesses. It is also designed using a 'black box' approach, so the algorithm used for cost calculations cannot be examined (Lai \& Mcculloch, 2017). The coding that the SAM software uses for cost calculations and system design, on the other hand, are known and accessible.

SAM has been developed by the USA National Renewable Energy Laboratories (NREL) in collaboration with Sandia National Laboratories in 2005 (National Renewable Energy Laboratory, 2017b) specifically to analyse solar energy technology.

Maybe in recognition of the limitations of other tools available, SAM has been used as a simulation tool by several scholars to evaluate the performance and financial feasibility of different types of renewable energy technologies. For example, DiOrio et al., (2015) evaluated the financial feasibility of integrating battery storage and solar PV in domestic buildings in the US using SAM. Poghosyan \& Hassan, (2015) assessed the techno-economic feasibility of Concentred Solar Power plants. Abdelhady et al,. (2018) evaluated techno-economic feasibility of biomass power plants. This study employs SAM to compare the performance and financial feasibility of a range of solar-plus-storage business models using different sizes of PV array and battery storage systems operating under different economic conditions.

Figure 3 shows the overview of employing SAM as a simulation tool to run a techno-economic analysis of integrating solar PV and electricity storage. Inputs to the model include weather data and solar irradiation of the project location, finnacial parmeters (e.g. interest rate, discount rate) and technical specification systems (e.g. project size, storage durations).

Figure 3.1: Techno-Economic Simulation of Integrating Solar PV and Storage in SAM The simulations have been run over the lifetime of the battery storage (15 years) (Gardiner, Schmidt, Heptonstall, Gross, \& Staffell, 2020; Spirit Energy Limited, 2018); these simulations were run based on hour by hour calculation of solar PV electric outputs and hour by hour of building electricity. 
. These results contain the following financial performance indicators:

- Multiyear annual cash flow and financial metrics

- Revenue from selling electricity and incentives payments

- Projects and partner IRR (for PPA projects)

- Levelized cost of electricity

- After-tax NPV (NPV)

\subsubsection{System Parameters}

Table 1 lists the key system parameters used in the simulation.

The building used was a high school located in London, England characterised by a typical electrical load profile as specified by the UK Energy Research (UKERC, 2013). The peak load was $22.8 \mathrm{~kW}$ and its total annual demand was 53,862.69 kWh.

Figure4: Electrical load profile for a typical school building Source: UKERC (2013)

Two scenarios characterised by $56 \mathrm{~kW}$ and $70 \mathrm{~kW}$ of solar PV arrays (Scenario A and B, respectively) were modelled, each connected to a $50 \mathrm{kWh}$ Lithium-Ion battery. Solar irradiation data was obtained from sub-hourly weather statistics for Gatwick Airport, a few miles south of London, covering the period 1990 to 2013 (National Renewable Energy Laboratory, 2017a). Assuming this level of solar irradiation, the SAM simulation tool predicted that $56 \mathrm{~kW}$ and 70 $\mathrm{kW}$ solar PV arrays (designated as Scenarios A and B) would generate 56,644 kWh 68,249 $\mathrm{kWh}$ of electricity, respectively, in the first year. Annual electricity generation was calculated assuming a $0.5 \%$ degradation factor for average PV output over a period of 20 years (Jones, Peshev, Gilbert, \& Mander, 2017).

It should be noted that a large solar PV array was selected to provide sufficient electricity surplus for charging the battery storage. Lithium-Ion storage was selected as these batteries 
are able to discharge and charge in response to signals from a demand-side manager. They are also comparatively durable over many recharging cycles, so few replacements would be required over the system lifetime (DiOrio et al., 2015). A battery's Demand Side Services (DSR) can be assessed by a number of performance parameters including: charge capacity, charge/discharge efficiency, the rate of charge/discharge, and the depth of discharge (Telaretti, Dusonchet, \& Palermo, 2016). Batteries that provide good DSR services should be able to discharge completely within a very short time and should have a long lifespan. For this study, a technical specification similar to the Tesla Powerpack (50 kWh) was used, as specified by Spirit Energy Limited (2018).

Table 1: Key System Parameters, complied from (Spirit Energy Limited, 2018)

\subsubsection{PV Generation and Battery Utilisation Model}

Using the system parameters above, a generation and battery utilisation model was developed with SAM to simulate the amount of electricity supplied to the building from both the solar PV array and the grid. Figure 5 shows the hourly load data for Scenario A (56kW solar PV array).

Figure 5: Electricity from Grid and System to Building Load for $56 \mathrm{~kW}$ solar PV System

\subsection{Financial Analysis}

The following sections provide an insight into the different economic and financial metrics which have been used in this study to investigate the financial viability of a CRE project employing solar-plus storage technology. It should be noted that SAM produces all financial results in US dollars (\$), so all results have been converted to sterling pounds (£) assuming a conversion rate of $\$ 1=£ 0.75$. 


\subsubsection{Net Present Value (NPV)}

NPV measures the economic feasibility of the project based on assessments of both revenues and costs. A positive NPV implies that the model is feasible. A discount cash flow analysis has been used in this study; the NPV was calculated for different economic scenarios involving a range of electricity prices, PV degradation rates and inverter replacement costs to reproduce the annual cash flow for the lifetime of the PV system.

The NPV was calculated using equation 1:

$N P V=\sum_{n=0}^{N} \frac{C_{n}}{(1+d \text { nominal })^{n}}$

Equation (1)

Where,

$$
\begin{aligned}
& C_{n}=\text { After tax cash flow } \\
& n=\text { Number of years } \\
& \mathrm{d}_{\text {nominal }}=\text { The nominal discount rate } \\
& \mathrm{N}=\text { Analysis period / project lifetime }
\end{aligned}
$$

The nominal discount rate was calculated using equation (2):

Nominal Discount Rate $\left(\mathrm{d}_{\text {nominal }}\right)=(1+$ Real Discount Rate $) \times(1+$ Inflation Rate $)-1$ Equation (2)

The discount rate is the primary factor affecting the NPV calculation. For community-owned solar projects which are mostly financed by community investors through a community share offer, the discount rate should be the same as or higher than the target for the return on investors' shares. The literature indicates that existing community-owned solar projects in the UK commonly return around $4.5 \%$ on equity/investment (Exeter Community Energy, 2017; South East London Community Energy, 2016). This compares with the 3.5\% return on social 
investment advocated by the UK government's 'Green Book' (Lowe, 2008). In this study, cash flow analyses were conducted with a real discount rate of $4.5 \%$ and an inflation rate of $2.5 \%$ (equivalent to a nominal discount rate of $7 \%$ ).

\subsubsection{The Levelized Cost of Electricity (LCOE)}

The LCOE is calculated using Equation (3) and represents the total project lifecycle costs, measured in pounds per kilowatt-hour $(£ / \mathrm{kWh})$. Expressed in another way, it is the minimum cost at which electricity can be sold to achieve break-even point over the lifetime of the project (Lai \& Mcculloch, 2017). Its calculation enables a comparison to be made between the impact on financial feasibility of different technologies, project sizes, capacities, and capital costs. Grid parity is defined as the situation where the LCOE for alternative energy production the same as the cost of purchasing power from grid.

$$
L C O E=\frac{-C_{0}-\frac{\sum_{n=1}^{N} z_{n}}{\left(1+d_{\text {nominal }}\right)^{n}}}{\frac{\sum_{n=1}^{N} Q_{n}}{\left(1+d_{\text {real }}\right)^{n}}}
$$

Equation (3)

Where,

$\mathrm{C}_{0}=$ the project's equity/capital investment

$\mathrm{Z}_{\mathrm{n}}=$ the annual project costs including; installation, operation and maintenance, financial costs and fees

$\mathrm{Q}_{\mathrm{n}}=$ the electricity generated by the system in year ' $\mathrm{n}$ ' as calculated using the weather data and the system performance parameters (such as degradation rate)

$N=$ the analysis period / lifetime of the project

$\mathrm{d}_{\text {real }}=$ the discount rate omitting inflation

$\mathrm{d}_{\text {nominal }}=$ the discount rate including inflation 
The LCOE also depends on installation and operating costs and financial parameters such as loan terms, loan rate, inflation, discount rate, inflation rate.

\subsubsection{Internal Rate of Return (IRR)}

The IRR is one of the most useful tools for measuring profitability and is the most commonly used method to calculate the rate of return (Rogers \& Duffy, 2012; Talavera et al., 2010). It is calculated using Equation (4).

$$
N P V=\sum_{n=0}^{N} \frac{C n}{(1+I R R)^{n}}=0
$$

Where

$\mathrm{N}=$ the analysis period / project lifetime

$\mathrm{C}_{\mathrm{n}}=$ after tax cash flow

\subsubsection{Cost Assumptions}

Total capital expenditure for the solar PV system simulated in this study was assumed to be $£ 900 / \mathrm{kW}$ (excluding grid connection), a baseline cost taken from a report prepared for Renewable Energy Associations (KPMG LLP, 2016). The capital expenditure for the battery storage was $£ 529 / \mathrm{kWh}$ (Woollaston and Curtis, 2018).

\subsubsection{Electricity Rate and Incentives}

An electricity price of $£ 0.14$ per kWh was used, based on that suggested by the Department of Business Energy and Industrial Strategy (2018) for a small non-domestic building. This is the fully delivered price, inclusive of standing charges ( $£ 0.66$ per day), Climate Change Levy and network charges (Distribution Use of System (DUoS) and Transmission Network Use of System (TNUoS), but excluding VAT.

Table 2: DUoS and TNUoS Charges for Half Hourly Metered Properties in London Source: London Power Network (2018) ; National Grid (2016) 
The DUoS unit charge is divided into three time-of-use band periods Red, Amber, and Green. These charges are usually different and depend on the type of meter (half-hourly or non-halfhourly), voltage type (high or low), time of use and location (region) and supply company (Eonenergy, 2018). The National Grid charges suppliers (and hence end users) for using the transmission network. The rate of TNUoS is location-specific and therefore based on the transmission demand tariff of the region (National Grid, 2016). The TNUoS are based on three separately observed peaks of the system across the year. These peak demands are measured over half hour intervals by National Grid and referred to as Triads. These typically occur in winter between the months of November and February in the late afternoon between 16:00 and 19:00. If an end user with storage capability can reduce their demand during the Triad period then they can reduce their TNUoS charges (National Grid, 2016). In order to access TNUoS avoidances the storage provider must be a partner with an energy supplier (Gillich et al., 2017). To simulate peak time prices, DUoS and TNoUS charges (see Table 2) were added to the electricity price for each time period (Business Electricity Prices, 2016; London Power Network, 2018).

\subsubsection{Evaluation of Demand Side Response (DSR) Revenues}

Electricity storage enables CRE projects to generate revenue by providing DSR and balancing services, thus potentially offsetting the loss of the FiT subsidy (Department of Business Energy and Industrial Strategy and Ofgem, 2017; Jones et al., 2017). DSR reflects the way end-users change their demand for electricity as a result of incentivising signals from their grid supplier (Behrangrad, 2015; Gillich et al., 2017). As far as conventional power companies are concerned, the aim of DSR is to encourage end-users to reduce their energy consumption during periods of peak demand (Rodríguez-Molina et al., 2014). Electricity storage means that CRE projects can generate income by providing DSR services, such as Firm Frequency 
Response (FFR), Frequency Control by Demand Management (FCDM), Short Term Operating Reserve (STOR), and Demand Turn UP (DTU).

Table 3:Potential Revenue Streams

Source: based on KPMG LLP, (2016); Power responsive (2016); Regen SW, (2016)

Of all these potential revenue streams (see Table 3 for a full list), STOR is probably the most promising. STOR is initiated when the actual demand on the grid is greater than the predicted demand. The STOR provider must be able to deliver at least $3 \mathrm{MW}$ of energy: (i) within 240 minutes of receiving instruction from the National Grid; (ii) for at least 2 hours; (iii) at least 3 times a week. These requirements can be met by aggregation from more than one CRE site.

In order to evaluate how much revenue can be generated from DSR services, the amount of stored electricity which is available for each hourly interval needs to be calculated. Each DSR service uses a slightly different method for revenue calculation, but according to Gillich et al. (2017) the combined DSR revenues can be approximately estimated using Equation 5:

$D S R$ Revenue $(€)=$ Electricity available $(k W h) \times$ Rate of $D S R \operatorname{services}\left(\frac{€}{k W h}\right)$ Equation (5)

In this study, the potential DSR revenue for each hour throughout the year was calculated based on the surplus generating capacity of the solar PV array after the building electricity load had been supplied.

\section{Results and Discussion}

As reported in Section 2, the Business Model Canvas devised by Osterwalder and Pigneur $(2005,2010)$ was used to develop a novel alternative business model for a community-owned solar PV system with integrated battery storage. This was followed by a series of technoeconomic analyses assuming several different economic strategies to test the model's financial and technical feasibility. This section presents the proposed model and the results of the techno- 
economic simulations.

\subsection{An Enhanced Business Model for Community-owned Solar Projects}

The proposed new business model aims to improve the financial robustness of an existing community-owned solar project by adding electricity storage. Designated as the 'Communityowned Energy Storage' model, it assumes that a CRE group have leased a space from a community building such as a school or care home in order to install both a solar PV array and battery storage. The solar electricity generated provides low-cost electricity for the community venue, and any electricity surplus is stored for use at peak price times, thus reducing the dependency of the host building on the grid (Figure 6).

Figure 6: 'Community-owned Energy Storage’ Business Model Operation

\subsubsection{Introduction of a Time of Use Power Purchase Agreement (TOU PPA)}

Selling cheap solar-generated electricity directly to host buildings through a Power Purchase Agreement (PPA) is a major source of revenue for most CRE projects. However, in many cases this approach is no longer sufficient to meet the projects' costs. Due to the reduction in FiT, the charge levied under the PPA would have to be the same or even higher than the grid, thus destroying the projects' former competitive advantage.

The addition of battery storage means that the loss in subsidy can be offset by providing balancing and DSR services to the grid, thus increasing the profitability of the project. However, in order to make such projects fully financially viable without any government incentives, it is desirable that they should still be able to sell electricity to host buildings at a lower price than buying electricity from the grid to be advantageous to the occupants.

In the 'Community-owned Energy Storage' Business Model, it is therefore proposed that occupants of the host building can buy and use the locally generated electricity under a Time 
of Use Power Purchase Agreement (TOU PPA) at any hour and in all seasons, irrespective of whether the solar PV array is producing energy at the time. Under the terms of a TOU PPA, the tariff charged to occupants of the host building depends on their time of use, thus maximising the additional income earned by the project. However, the CRE project would always aim to undercut the cost of grid electricity, thus enabling occupants to avoid network charges and achieve a significant saving on their electricity bills.

A 'TOU PPA' model of this type was successfully adopted by the California Public Utilities Commission (CPUC) in 2005. Renewable energy developers sold electricity to California Utility at prices based on a number of the factors, including available capacity, time of day, and the season (Salazar \& Johnson, 2006).

\subsubsection{Characteristics of the 'Community-owned Energy Storage' Model}

Figure 7 shows how the 'Community-owned Energy Storage' model was designed using the four fundamental categories of the Business Model Canvas.

The customer segment of the model includes both the occupants of the host building, to whom the CRE group sells generated electricity at a lower cost than the grid based on the time of use, and the licensed supplier and/National Grid, for which the project provides balancing and DSR services.

The key infrastructure and resources required are a rooftop solar PV array, electricity storage, a smart meter and Wi-Fi.

Figure 7: Business Model Structure 'Community-owned Energy Storage' for Solar PV Projects Source: Based on Osterwalder and Pigneur (2010)

It should be noted that this business model requires more expertise than existing CRE projects based on a low-risk FiT model. The efficient use of rechargeable batteries and the provision of 
DSR services to the grid both demand extra technical and business knowledge.

\subsubsection{Provision of DSR Services under Community-owned Energy Storage Model}

An important element in the proposed model is the provision of DSR services. These can be delivered either by a single CRE project with a large amount of surplus capacity or by a number of projects aggregating their unused storage (Power responsive, 2016). Since the amount of space available for battery storage in most of the buildings leased by CRE projects is likely to be small, the model proposed in this study works in partnership with an Aggregator and local supplier.

The Aggregator works with System Operator (SO) to deliver balancing and DSR services to a local utility company supplying grid electricity or to the National Grid itself. Usually this collaboration employs cloud-based tools that aggregate all the stored energy available, including not only the battery storage attached to the CRE project, but also any stationary or mobile storage that may be owned by households connected to the system (e.g. electric vehicles).

Figure 8: Provision of DSR Services Under ‘Community-Owned Energy Storage’ Model

Figure 8 illustrates how the 'Community-owned Energy Storage' operates in this respect. The aggregated storage creates a virtual energy pool which can be sold to the grid to maintain stable supply especially at times of peak demand (i.e. a STOR event). Each storage provider receives payment based on the energy capacity or the reduction in demand they provide in response to a signal received from the Aggregator at the time of STOR event. Storage providers of course pay the Aggregator a fee for their administrative agency.

The current movement nationally away from conventional power stations and toward renewable energy means that the margins of spare capacity available to the energy industry are narrowing. This in turn is creating market conditions that incentivise utility companies to work 
with local storage providers and generator. Due to changes in industry rules, it is now very expensive for a supplier to generate or consume more than they have contracted, so suppliers are beginning to encourage customers to own storage by paying them for DSR services (missioncriticalpower, 2016). Working in partnership with suppliers that invite DSR participation in this way there is a clear opportunity for CRE groups to improve the viability of their projects by adding storage technology.

\subsection{Techno-Economic Assessment of the 'Community-owned Energy Storage' Model}

Having described the structure and operation of the proposed 'Community-owned Energy Storage' model, this section reports a series of techno-economic analyses that were conducted to assess its feasibility. Table 4 summarises the three economic strategies that were simulated.

Table 4: Summary of the Techno-Economic Strategies examined

A 'loan and community share' financing model was used. The results indicate that, to become financially viable in the current post-subsidy situation, a CRE group needs to have access to zero interest loans for at least half of the cost of installing its solar-plus-storage system, the remainder of the capital cost being raised through a community share (equity) offer, thus increasing the project's NPV. Based on the findings of an earlier report, a community share offer with a $4.5 \%$ return on investment has been modelled for this study (Exeter Community Energy, 2017; South East London Community Energy, 2016). Table 5 outlines all the financial parameters that have been used to conduct the cash flow analysis.

Table 5: Financial Parameter for Community-owned Energy Storage Model

Analysis showed that, by including current battery replacement costs the operating and 
maintenance costs increases considerably and the business model would not be financially attractive due to a more extended payback period. Since this is a long-term concern it was decided to exclude battery replacement from the techno-economic simulations and conduct the assessment over an assumed lifetime for the battery storage of 15 years.

\subsubsection{Strategy 1: Financial Analysis of Providing STOR Services}

In order to benefit from STOR revenue, storage must be available three times a week and provide reliable demand reductions during specified 'availability windows' when STOR services are most likely to be needed. In this study, due to intermittent nature of solar PV it has been modelled that battery storage to get charged with electricity generated by the solar PV system during the day, and will be discharged in the evening in response to a signal from the Aggregator. Therefore, only an evening availability window (Window 2 in Figure 9) has been assessed.

Figure 9: Availability and Utilisation Windows for Providing STOR Services through 24 Hours Source: Eddie Proffitt (2017)

Due to their third party structure, CRE projects are not usually able to charge their batteries from the grid at off-peak rates. So in order to assess the potential for STOR, the battery storage was programmed to be fully charged from the solar PV before the generated electricity was made available to meet the building demand, particularly between November and February when solar energy generation is low. The storage was also programmed to be fully charged from the solar PV at the weekend, when no electricity was required to meet the building demand. The stored energy was thus always available to provide STOR demand reduction during the week (Table 6).

Table 6: Battery Charging and Discharging Schedule for Strategy 1 (STOR services) 
Figure 3: Strategy 1: Providing STOR Services by CRE Group in the host building

Figure 9 illustrates the delivery of STOR by community-owned solar projects in March under Strategy 1. The simulation results presented in Figure 9 show that, under Strategy 1, the project could deliver a steady demand reduction between 17:00 and 19:00 (the utilisation window) by going off-grid for 2 hours (red line) and using stored electricity to meet the building electricity demands (blue line).

An Aggregator fee of $15 \%$ was considered to be appropriate for a social enterprise of this kind (Gillich et al., 2017). This fee covers the cost of any penalties, as well as that of communication and monitoring technologies. The results indicate that the community-owned storage model could potentially generate $£ 1,553$ annually for the period of 15 years by providing STOR services (Table 7).

Table 7: Revenue from Providing STOR Services

Source: based on Gillich et al. (2017)

\subsubsection{Strategy 2: Financial Analysis of Providing DSR Services for a Supplier}

In addition to income from STOR, the project could also benefit by providing DSR services for the supplier twice during the day: first, in the morning when solar generation is typically very high; and second, in the evening when electricity demand on the grid is very high.

In order to investigate the techno-economic feasibility of this, the storage was programmed to be charged from the solar PV array from 11:00 to 14:00 throughout the year and be discharged between 16:00 and 19:00, which is the normal period of peak electricity demand (Table 8). 
Table 8: Battery Charging/Discharging Schedule for Providing DSR Services by CRE Groups under the Alternative Business Model

Figure 11 indicates that the occupants of the host building are able to reduce demand on the grid successfully by utilising the project's stored energy according to this schedule. The battery storage discharges (orange line) between 16:00 to 19:00, so the building is off-grid during the peak demand period (blue line).

Figure 11: Providing DSR Services for Supplier by CRE Groups Strategy 2, in the host building

The provision of DSR services would earn a payment from a supplier based on the reduction in load on the grid. Based on the actual balancing costs of conventional utility companies, the simulation assumes a payment of $£ 0.10$ per $\mathrm{kWh}$ for providing DSR services between 11:00 and 14:00, and between 16:00 and 19:00 each day (Elexon, 2013; missioncriticalpower, 2016). Table 9 shows that this would amount to an annual income of $£ 9,282$.

Table 9: Annual Revenue from Only Providing DSR Services for supplier under Community-owned Storage

\subsubsection{Strategy 3: Financial Analysis of Selling Electricity through a 'TOU PPA'}

As explained in section 3.1.1 above, solar-plus-storage projects can sell electricity to occupants of a host building through an advantageous 'TOU PAA' tariff, thus providing another source of revenue to help offset the loss of FiT. In the simulation performed for this study, the 'TOU PPA' tariff enables occupants to buy their electricity based on the time of their use, at two different rates of $£ 0.09$ per $\mathrm{kWh} £ 0.13$ per $\mathrm{kWh}$. These prices are lower than the price offered by the National Grid (Table 10). Also, these designated prices compare well with TOU prices in other studies (Gardiner et al., 2020; Teng \& Strbac, 2016).

The results of the simulation indicate that, by taking advantage of a 'TOU PPA' tariff, the host building would save a staggering $£ 24,525$ in annual electricity bills (see Table 12 ). Thus, as a 
result of hosting the solar-plus-storage system the building can potentially use solar-generated electricity almost all day, even when the sun is not shining, and save a very significant amount of money (Figure 12).

Table 11 outlines the total TOU PPA revenues that the project could generate from a $56 \mathrm{~kW}$ or $70 \mathrm{~kW}$ solar PV array. The CRE group would need to have a contract with a conventional utility company for the supply of electricity to the host building on those comparatively rare occasions when neither its solar PV nor storage can meet the demand. The simulation assumes that the licenced supplier would supply this electricity to the host at the same price as the TOU PPA tariff.

Table 10: Comparing TOUPPA Price (proposed in this study) to a Normal Non-Domestic Electricity Price in London $^{l}$

Figure 12: CRE Project Providing Electricity to the Host Building Based on 'TOU PPA' Strategy

Table 11: Annual Revenue of Selling electricity through 'TOU PPA'

'TOUPPA' tariff in addition to making community-owned solar projects financially viable it also provides an opportunity for the tenant of the host building to save significantly on their electricity bills by buying low price solar generated electricity and avoiding network charges. Results of this study indicate by up taking 'TOUPPA' tariff residents of the host building potentially would save $£ 24,525$ on their electricity bills (Table 12). Teng \& Strbac (2016) also highlighted that the solar PV plus storage through advanced pricing such as TOU

\footnotetext{
${ }^{1}$ Network charges including Transmission Use of System and Distribution Use of system are included to price of electricity.
} 
increase profitability of these projects at the community level.

Table 12: Host Building Tenant's Electricity Cost Savings with System and 'TOU PPA'

\subsubsection{Combining all Three Sources of Revenue (DSR, STOR and PPA)}

The simulation results indicate that the community-owned storage model is most economically attractive if the CRE group can utilise all three sources of revenue (Table 13). The results of this paper are consistent with both findings of Gardiner, et al. (2020) and Teng \& Strbac (2016) who observed that combining different revenue schemes can increase the viability of solar PV plus storage projects.

Table 13: Scenario 3 Financial Metric; under the Alternative Business Model, Including DSR, STOR and TOU PPA Revenue

Contracting for both DSR services and STOR might prove challenging as it means that the project is in effect being paid twice: first for charging the battery and then for discharging it. However, it is technically feasible. If it is not possible to contract for all three services, then the priority should be given to combining DSR and 'TOU PPA' as this generates more revenue than combining STOR and 'TOU PPA' (Table 14). It should be also noted that there might be some instances that the developed model gives priority to using energy charged by the battery to serve building load through 'TOU PPA' and might not be able to earn DSR revenue. Evaluating the impact of such prioritization on the overall income of the project is out of the scope of this study, and should be studied in the practice. This is due to the fact that in this paper simulations are run for to show the novelty of the developed business model and more detailed analysis is, therefore, needed to be done in the practice.

Table 14: Total Gross Revenue all Three Sources Revenue for Year 1 (DSR, STOR and PPA)

\subsubsection{Validating the Feasibility and Replicability of the Alternative Business Model}

In order to assess whether the simulation findings would be replicated for smaller systems, the 
modelling was finally repeated with a $34 \mathrm{~kW}$ Solar PV array and with 2 different sizes of storage ( $28 \mathrm{kWh}$ and $21 \mathrm{kWh}$ ). Storage with a capacity lower than $50 \mathrm{kWh}$ is not usually permitted to provide grid services, so these smaller systems can only benefit from selling electricity through a 'TOU PPA' and by providing DSR services for a supplier. However, as Table 15 shows, the model remains financially viable with both the smaller storage sizes. A system with a battery capacity larger than $50 \mathrm{kWh}$ would, nevertheless, be more desirable as it offers a higher NPV.

Table 15: Financial Metric for CRE Projects with Smaller System under the Alternative Business Model

\subsection{Sensitivity Analysis}

A series of analyses with different ranges of parameters including IRR (between $4.5 \%$ and $6.5 \%)$, return on investment $(4.5 \%$ and $6.5 \%)$, various sizes of battery storage (between 25 $\mathrm{kWh}$ and $50 \mathrm{kWh}$ ), various sizes of solar PV (between $35 \mathrm{~kW}$ and $70 \mathrm{~kW}$ ) and building demands (15\% decrease and $15 \%$ increase of demand) have been conducted to investigate key factors influencing the economic performance of the 'Community-Owned Energy Storage' model.

Results indicated that IRR and return on investment are key determinant factors of the profitability of the model. The analyses showed that with an increase in IRR and rate of return on investment, the project NPV also increases, in particular, these changes are significant for projects with larger solar PV. For instance, if a project with $70 \mathrm{~kW}$ solar and $50 \mathrm{kWh}$ storage capacity has both IRR and the return on investment of $6.5 \%$, the project NPV, will be $£ 38,990$ which is almost $6 \%$ higher than the NPV $(£ 36,803)$ of a similar project with both IRR and return on investment of $4.5 \%$. However, the same rates for a project with $56 \mathrm{~kW}$ solar PV and $50 \mathrm{kWh}$ storage increases the NPV only by $0.06 \%$. 
Results showed that changes in annual building demand do not have a significant impact on the financial performance of community-owned solar projects. This is due to the fact that for these type of projects, initially, CRE organisation would agree through Power Purchase Agreement (PPA) to provide a certain amount of electricity to a host building based on the size of their system (Solar PV and storage capacity) and annual prediction of solar generation. Consequently, these project revenues are more dependent on solar system generation and storage capacity rather than changes in building demand. However, it should be noted that building demand should still be considered for this type of project as it is a factor which determines the size of the system unless the building has an exceptionally large roof area to volume ratio.

\section{Conclusion and Policy Implications}

This study has demonstrated that the integration of solar PV generation with the advanced battery technology that is now available can completely offset the loss in income due to the withdrawal of FiT. The business model developed for the simulated 'Community-owned Energy Storage' project can fully restore the economic feasibility of CRE projects in the postsubsidy situation and enable them to play a vital role in the decentralisation and decarbonisation of the UK's electricity market.

Because it is community-owned, the project also permits low-income and fuel-poor households to benefit from energy costs that are considerably lower than those provided by the National Grid.

The model's design does not depend on any special local circumstances, but it does require more technical and business expertise than current CRE business models. For this reason, it is recommended that CRE groups that wish to move in the direction of solar-plus-storage should work in partnership with an Aggregator and a local licenced supplier.

The implementation of the 'Community-owned Energy Storage' model would be greatly 
encouraged by the following government policy initiatives:

i. The UK's localised renewable energy schemes should be enabled to sell their electricity directly to local customers. This study, therefore, proposes that the UK government should promote and facilitate the Time of Use Power Purchase Agreement ('TOU PPA') for CRE projects.

ii. In order to reduce the risks associated with developing such an innovative business model, CRE groups should have access to zero interest loans for part of their projects, at least until the cost of battery storage falls further. The UK government could facilitate such loans by restoring the Urban Community Energy Fund (UCEF).

iii. The UK's energy suppliers should be encouraged to involve CRE projects with integrated storage in the provision of demand-side response services. This would be a 'win-win' situation for both parties, as it enables the supplier to reduce their balancing costs and makes the CRE projects more financially robust.

iv. The government should help CRE groups that wish to adopt storage technology by offering technical training and promoting partnerships with Aggregators and local suppliers.

\subsection{Avenue for further research}

One of the key results of this paper was developing alternative business models for localised and community based solar PV schemes. However, it was beyond the scope of its research resources to validate the model in practice. Consequently, it would be advantageous to validate the community-owned energy storage business model in the context of some real case-studies employing a range of non-domestic buildings with varying building loads. 


\section{References}

10:10 Climate Action. (2016). Community energy The way forward. Retrieved from https://1010uk.org/articles/community-energy-way-forward

Aslani, A., \& Mohaghar, A. (2013). Business structure in renewable energy industry: Key areas. Renewable and Sustainable Energy Reviews, 27, 569-575. https://doi.org/10.1016/j.rser.2013.07.021

Asmus, P. (2008). Exploring New Models of Solar Energy Development. The Electricity Journal, 21(3), 61-70. https://doi.org/10.1016/j.tej.2008.03.005

Bidmon, C., \& Knab, S. (2014). The Three Roles of Business Models for Socio. The XXV ISPIM Conference. Retrieved from https://www.researchgate.net/publication/263065156_The_Three_Roles_of_Business_Models_for_SocioTechnical_Transitions

Bocken, N. M. P., Short, S. W., Rana, P., \& Evans, S. (2014). A literature and practice review to develop sustainable business model archetypes. Journal of Cleaner Production, 65, 42-56. https://doi.org/10.1016/j.jclepro.2013.11.039

Bronski, P., Creyts, J., X, M. C., Doig, S., Glassmire, J., Energy, H., ... Butler, T. (2015). THE ECONOMICS OF LOAD DEFECTION (Exec summary). Retrieved from http://www.rmi.org/cms/Download.aspx?id=11581\&file=2015-06_RMI-TheEconomicsOfLoadDefectionExecSummary.pdf

Bruch, M., \& Müller, M. (2014). Calculation of the cost-effectiveness of a PV battery system. Energy Procedia, 46, 262-270. https://doi.org/10.1016/j.egypro.2014.01.181

Business Electricity Prices. (2016). Unit kWh Prices for Business Electricity, 1-7. Retrieved from http://www.businesselectricityprices.org.uk/cost-per-kwh/

Cherrington, R., Goodship, V., Longfield, A., \& Kirwan, K. (2013). The feed-in tariff in the UK: A case study focus on domestic photovoltaic systems. Renewable Energy, 50, 421-426. https://doi.org/10.1016/j.renene.2012.06.055

Department for Business Energy \& Industrial Strategy. (2017). Upgrading Our Energy System.

Department of Business Energy and Industrial Strategy and Ofgem. (2017). Upgrading Our Energy System Smart Systems and Flexibility Plan. Retrieved from

https://www.gov.uk/government/uploads/system/uploads/attachment_data/file/633442/upgrading-ourenergy-system-july-

2017.pdf\%0Ahttps://www.gov.uk/government/uploads/system/uploads/attachment_data/file/631656/smart -energy-systems-summaries-responses.pdf

Eddie Proffitt. (2017). Profiting from Demand Side Response, 1, 0. https://doi.org/10.1016/j.trd.2008.11.010

Elexon. (2013). Imbalance Pricing Guidance, (November 2013), 1-50.

Eonenergy. (2018). Distribution Use of System Recovering the cost of distributing electricity across the national network. Retrieved January 14, 2018, from https://www.eonenergy.com/for-your-business/large-energyusers/understand-energy/ /media/PDFs/For-your-business/Large-Energy-Users/3rd Party Charges/DUoS charge.pdf

Eunimia. (2016). Investing in UK Electricity Storage, (January). Retrieved from http://www.eunomia.co.uk/reports-tools/investing-in-uk-electricity-storage/

Everett, Robert; Boyle, Godfrey; Peake, Stephen and Ramage, J. eds. (2012). Energy Systems and Sustainability: Power for a Sustainable Future (2nd ed.). Retrieved from http://ukcatalogue.oup.com/product/9780199593743.do

Exeter Community Energy. (2017). Community Share Offer. Retrieved May 26, 2018, from https://www.ecoe.org.uk/

Gardiner, D., Schmidt, O., Heptonstall, P., Gross, R., \& Staffell, I. (2020). Quantifying the impact of policy on the investment case for residential electricity storage in the UK. Journal of Energy Storage, 27(November 2019), 101140. https://doi.org/10.1016/j.est.2019.101140

Gillich, A., Ford, A., Zagoni, C., Hewitt, M., Oakes, G. (2017). A smarter way to electrify heat - the balanced energy network approach to demand side response in the UK. ECEEE Summer Study Proceedings Consumption, Efficiency \& Limits, 1153-1163.

Gilman, P. (2014). System Advisor Model ( SAM ) Time Step for SAM Model Simulations, 5-11. Retrieved from https://sam.nrel.gov/node/69179

Hoppmann, J., Volland, J., Schmidt, T. S., \& Hoffmann, V. H. (2014). The economic viability of battery storage for residential solar photovoltaic systems - A review and a simulation model. Renewable and Sustainable Energy Reviews, 39, 1101-1118. https://doi.org/10.1016/j.rser.2014.07.068

Huijben, J. C. C. M., \& Verbong, G. P. J. (2013). Breakthrough without subsidies? PV business model experiments in the Netherlands. Energy Policy, 56(January 2012), 362-370. https://doi.org/10.1016/j.enpol.2012.12.073

International Energy Agency. (2017). Key world energy statistics. Retrieved from 
https://www.iea.org/publications/freepublications/publication/KeyWorld2017.pdf

Johnson, M. W., \& Suskewicz, J. (2009). How to Jump-Start the Clean Tech Economy. Harvard Business Review, 87(November), 52-60. https://doi.org/10.1038/scientificamericanearth0309-22

Jones, C., Peshev, V., Gilbert, P., \& Mander, S. (2017). Battery storage for post-incentive PV uptake? A financial and life cycle carbon assessment of a non-domestic building. Journal of Cleaner Production, 167, 447-458. https://doi.org/10.1016/j.jclepro.2017.08.191

KPMG LLP. (2016). Development of decentralised energy and storage systems in the UK. Retrieved from http://www.r-e-a.net/upload/rea_storage_report-web_accessible.pdf

Lai, C. S., \& Mcculloch, M. D. (2017). Levelized cost of electricity for solar photovoltaic and electrical energy storage. Applied Energy, 190, 191-203. https://doi.org/10.1016/j.apenergy.2016.12.153

London Power Network. (2018). London Power Networks plc Use of System Charging Statement, (03929195). Retrieved from http://www.businesselectricityprices.org.uk/cost-per-kwh/

Lowe, J. (2008). Intergenerational wealth transfers and social discounting: Supplementary Green Book guidance. HM Treasury, London, (July), 3-6.

Maloney, P. (2018). McKinsey: Cheaper batteries load defection for utilities present imminent threat of load defection for utilities. Retrieved from https://www.utilitydive.com/news/mckinsey-cheaper-batteriespresent-imminent-threat-of-load-defection-for-u/446193/

Mariaud, A., Acha, S., Ekins-Daukes, N., Shah, N., \& Markides, C. N. (2017). Integrated optimisation of photovoltaic and battery storage systems for UK commercial buildings. Applied Energy, 199, 466-478. https://doi.org/10.1016/j.apenergy.2017.04.067

Mirzania, P. (2018). DEVELOPING VIABLE SELF-SUSTAINING COMMUNITYOWNED SOLAR PV PROJECTS IN THE UK THROUGH BUSINESS MODEL INNOVATION.

Mirzania, P., Ford, A., Andrews, D., Ofori, G., \& Maidment, G. (2019). The impact of policy changes: The opportunities of Community Renewable Energy projects in the UK and the barriers they face. Energy Policy, 129(November 2017), 1282-1296. https://doi.org/10.1016/j.enpol.2019.02.066

missioncriticalpower. (2016). Batteries included : Government backs plan to ramp up smart grid and battery storage. Retrieved June 10, 2018, from https://missioncriticalpower.uk/batteries-included-governmentbacks-plan-to-ramp-up-smart-grid-and-battery-storage

National Grid. (2016). Transmission Network Use of System Charges. Nationalgrid. Retrieved from http://www2.nationalgrid.com/UK/Industry-information/System-charges/Electricitytransmission/Transmission-network-use-of-system-charges/

National Renewable Energy Laboratory. (2017a). National Solar Radiation Database. Retrieved from https://nsrdb.nrel.gov/api-instructions

National Renewable Energy Laboratory. (2017b). System Advisor Model ( SAM ) Welcome to SAM. Retrieved October 1, 2018, from https://sam.nrel.gov/

Nicholas DiOrio, Aron Dobos, A., \& Janzou, S. (2015). Economic Analysis Case Studies of Battery Energy Storage with SAM, (November).

Nolden, C. (2013). Governing community energy-Feed-in tariffs and the development of community wind energy schemes in the United Kingdom and Germany. Energy Policy, 63, 543-552. https://doi.org/10.1016/j.enpol.2013.08.050

Ofgem. (2019). Changes to the FIT scheme. Retrieved from https://www.ofgem.gov.uk/environmentalprogrammes/fit/about-fit-scheme/changes-fit-scheme

Osterwalder, A. (2004), the Business Model Ontology a Proposition in a Design Science Approach. https://doi.org/10.1017/CBO9781107415324.004

Osterwalder, A., \& Pigneur. (2010). Business model generation: a handbook for visionaries, game changers, and challengers. (Vol. 30). https://doi.org/10.1523/JNEUROSCI.0307-10.2010

Power responsive. (2016). Demand Side Flexibility Annual Report 2016 Executive summary. Retrieved from http://powerresponsive.com/wp-content/uploads/2017/01/Power-Responsive-Annual-Report-2016FINAL.pdf

Regen SW. (2016). Energy Storage - Towards a commercial model - 2 nd Edition. Retrieved from https://www.regen.co.uk/wp-content/uploads/P2P_-_Energy_storage_-_2nd_Edition__DIGITAL_FILE_Singles.pdf

RegenSW and Scown, S. (2016). Local Supply: Options for Selling Your Energy Locally, (March). Retrieved from https://www.regensw.co.uk/7283018298372873/wp-content/uploads/2015/06/Regen-White

Richter, M. (2011). Business model innovation for sustainable energy : German utilities and renewable energy. Centre for Sustainability Management (CSM) Leuphana Universität Lüneburg, 1-29. Retrieved from http://www2.leuphana.de/umanagement/csm/content/nama/downloads/download_publikationen/Richter_ Business Model Innovation for Sustainable Energy Ge

Rodríguez-Molina, J., Martínez-Núñez, M., Martínez, J.F. and Pérez-Aguiar, W. (2014). Business Models in the Smart Grid: Challenges, Opportunities and Proposals for Prosumer Profitability. Energies, 6142-6171. 
https://doi.org/10.3390/en7096142

Rogers, M., \& Duffy, A. (2012). Engineering Project Appraisal. Retrieved from https://books.google.com/books?id=ayv_fxVR6pwC\&pgis=1

Salazar, R., \& Johnson, D. (2006). A Summary and Comparison of the Time of Delivery Factors Developed by the California Investor-Owned Utilities for Use in Renewable California Energy Commission, (August 2006).

Sani Hassan, A., Cipcigan, L., \& Jenkins, N. (2017). Optimal battery storage operation for PV systems with tariff incentives. Applied Energy, 203, 422-441. https://doi.org/10.1016/j.apenergy.2017.06.043

South East London Community Energy. (2016). Share Offer 2016. Retrieved October 12, 2016, from http://selce.org.uk/wp-content/uploads/2016/07/SELCE-Share-Offer-2016-FINAL-Low-Res.pdf

Spirit Energy Limited. (2018). Battery Storage Knowledge Bank Tesla Powerpack. Retrieved January 30, 2018, from https://www.spiritenergy.co.uk/kb-batteries-tesla-powerpack

Stephan, A., Battke, B., Beuse, M. D., Clausdeinken, J. H., \& Schmidt, T. S. (2016). Limiting the public cost of stationary battery deployment by combining applications. Nature Energy, 1(7), 1-6. https://doi.org/10.1038/nenergy.2016.79

Talavera, D. L., Nofuentes, G., \& Aguilera, J. (2010). The internal rate of return of photovoltaic grid-connected systems: A comprehensive sensitivity analysis. Renewable Energy, 35(1), 101-111. https://doi.org/10.1016/j.renene.2009.07.006

Telaretti, E., Dusonchet, L., \& Palermo, U. (2016). Battery storage systems for peak load shaving applications. IEEE 16th International Conference on Environment and Electrical Engineering (EEEIC).

Teng, F., \& Strbac, G. (2016). Business cases for energy storage with multiple service provision. Journal of Modern Power Systems and Clean Energy, 4(4), 615-625. https://doi.org/10.1007/s40565-016-0244-1

UKERC. (2013). Industrial Energy Use from a Bottom-Up Perspective: Developing the Usable Energy Database (Vol. 2010). Retrieved from http://data.ukedc.rl.ac.uk/simplebrowse/edc/efficiency/industry/EnergyConsumption

United Nations Foundation. (2015). Paris Agreement. Retrieved from https://unfoundation.org/what-wedo/issues/energy-and-climate/

Woollaston, V and Curtis, M. (2018). Tesla-powerwall-2-uk-price-specs-release-date. Retrieved March 11, 2018, from http://www.alphr.com/tesla/1003563/tesla-powerwall-2-uk-price-specs-release-date 